\title{
Vivência da maternidade para presidiárias
}

\section{Motherhood experience for prisoners}

Lannuzya Veríssimo e Oliveira ${ }^{1}$, Francisco Arnoldo Nunes de Miranda ${ }^{2}$, Gabriela Maria Cavalcanti Costa ${ }^{3}$

Enfermeira, Mestre em Saúde Pública. Professor Assistente da Universidade Federal do Rio Grande do Norte. Natal, RN, Brasil. E-mail: lannuzyacg@hotmail.com.

2 Enfermeiro, Doutor em Enfermagem. Professor Associado da Universidade Federal do Rio Grande do Norte. Natal, RN, Brasil. E-mail: farnoldo@gmail.com.

${ }^{3}$ Enfermeira, Doutora em Enfermagem. Professor Titular da Universidade Estadual da Paraíba. Campina Grande, PB, Brasil. E-mail: gabymcc@bol.com.br.

\section{RESUMO}

O estudo teve como objetivo compreender a vivência da maternidade para presidiárias. Trata-se de um estudo exploratório-descritivo com abordagem qualitativa realizado com 17 mulheres reclusas no Sistema Penitenciário do Estado da Paraíba, no período de julho a dezembro de 2012. Para coleta de dados utilizou-se um questionário sociodemográfico e entrevista semiestruturada. Os dados foram organizados e categorizados segundo análise de conteúdo, gerando três categorias: sofrimento pela separação; consolo em meio à angústia; fragmentação familiar. Os resultados apontaram que a vivência da maternidade no ambiente prisional é permeada por sofrimentos e limitações. No entanto, a permanência da criança junto à mãe gera consolo em meio à angústia e minimiza, mesmo que temporariamente, as dificuldades no cárcere. É mister implantar ações intersetoriais que favoreçam a relação mãe e filho no contexto do aprisionamento.

Descritores: Saúde da Mulher; Enfermagem Obstétrica; Relações Mãe-Filho; Prisões; Prisioneiros.

\section{ABSTRACT}

The study aimed to understand the motherhood experience for prisoners. This is an exploratory-descriptive qualitative study conducted with 17 prisoner women in the Penitentiary System of Paraíba State, during the period of July to December of 2012. A sociodemographic questionnaire and semi-structured interviews were used for data collection. Data were organized and categorized following content analysis, generating three categories: separation suffering; comfort during anguish; family fragmentation. Results pointed out that motherhood experience in the prison is permeated by suffering and limitations. However, the presence of their child creates comfort during anguish and minimize difficulties in prison, although temporarily. It is necessary to create inter sectoral actions to favor the motherchild relationship in the prison context.

Descriptors: Women's Health; Obstetric Nursing; Mother-Child Relations; Prisons; Prisoners. 


\section{INTRODUÇÃO}

O crescimento da população feminina encarcerada no Brasil é de aproximadamente $12 \%$ ao ano. Segundo dados do Sistema Integrado de Informações Penitenciárias (InfoPen), em julho de 2013, a população carcerária brasileira era de 548.003 pessoas. De acordo com essa mesma fonte, a Paraíba apresenta 8.723 pessoas em situação de privação de liberdade, sendo 8.149 homens e 574 mulheres $^{(1)}$. Embora o número de mulheres seja significativamente inferior ao de homens encarcerados, devido à função social historicamente atribuída às mulheres de esposa, cuidadora e, em muitas famílias, provedora do sustento, o aprisionamento feminino gera múltiplas implicações, inclusive no âmbito da saúde pública ${ }^{(2)}$.

As mulheres em privação de liberdade tendem a ser jovens, de baixo nível socioeconômico e educacional, mães solteiras, afrodescendentes, com história de prostituição e uso abusivo de drogas ${ }^{(3)}$. Por serem, em sua maioria, jovens e, portanto, encontrarem-se em idade reprodutiva, a gravidez e, consequentemente, a maternidade são situações recorrentes durante o cumprimento da pena ${ }^{(4)}$.

Atento as demandas de saúde das mulheres presas, o Plano Nacional de Saúde no Sistema Penitenciário (PNSSP), instituído pela Portaria Interministerial n.1777/2003 ${ }^{(5)}$, bem como o Pacto Nacional pela Redução da Mortalidade Materna e Neonatal lançado em 2004, trazem diretrizes que enfatizam o direito à assistência à saúde da mulher presa, com ênfase no período gravídicopuerperal, garantido, inclusive, o direito ao aleitamento materno $^{(6)}$.

No entanto, ao abrigo das recomendações e pactos para garantir a saúde da mulher presa, o sistema penitenciário brasileiro é reconhecidamente deficiente quanto à assistência à saúde da população encarcerada ${ }^{(7)}$. Além disso, o fato das prisões não terem sido inicialmente pensadas e projetadas para mulheres, mas para homens, tendo em vista uma visão racional que compreendia a periculosidade como característica inerente a eles ${ }^{(8)}$.
Mesmo tendo aumentado com o advento do século $X X$, as prisões femininas continuam inadequadas para abrigar/disciplinar as mulheres em situação de encarceramento $^{(9)}$.

Ademais, as questões envolvendo a saúde da mulher, no transcurso das políticas públicas do Brasil e, de uma forma generalizada, no mundo, dizem respeito a garantia da redução da mortalidade materna e infantil, com medidas e serviços de atenção à saúde desse binômio. Todavia, sabe-se que para mulheres encarceradas destacam-se as dificuldades de acesso aos serviços de saúde $^{(3)}$. Assim, pressupõe-se que no contexto do encarceramento, a maternidade ganha contornos distintos daqueles vivenciados por mulheres em liberdade.

Sobre a saúde das mulheres no contexto do encarceramento, observa-se que a produção científica é escassa ou pouco estudada, abordando prioritariamente aspectos referentes ao processo saúde-doença das mulheres presas, em detrimento à aspectos relacionados a subjetividade que permeia o encarceramento, o que negligencia o direito da mulher presa de ser compreendida em suas reais necessidades ${ }^{(10)}$.

Frente ao exposto, questionou-se: como é a vivência da maternidade em penitenciárias? A justificativa e relevância do presente estudo diz respeito a visibilidade de uma situação mascarada e silenciada pela sociedade em geral, e pelos mecanismos de regulação e prestação da assistência do Sistema Único de Saúde. Mediante tais considerações desenvolveu-se esta pesquisa com o objetivo de compreender a vivência da maternidade para presidiárias.

\section{CAMINHO METODOLÓGICO}

Estudo exploratório-descritivo com abordagem qualitativa realizado entre os meses de julho a dezembro de 2012 nas quatro penitenciárias femininas subordinadas à Secretaria de Estado da Administração Penitenciária da Paraíba (SEAP): Instituto de Recuperação Feminina Maria Júlia Maranhão; Penitenciária Feminina 
de Campina Grande; Presídio Feminino de Patos e Penitenciária Padrão de Cajazeiras, que abrigavam, respectivamente, 420, 57, 61 e 24 mulheres cumprindo pena em regime fechado.

O Instituto de Recuperação Feminina Maria Júlia Maranhão foi o único construído com a finalidade de abrigar mulheres em situação de prisão judicial e que possui Equipe de Saúde no Sistema Penitenciário, seguindo recomendação do PNSSP. As demais penitenciárias são espaços adaptados, que outrora, eram utilizados para abrigar a população carcerária masculina. Apenas as penitenciárias de João pessoa e Patos possuem Unidades Materno-Infantil.

As quatro instituições prisionais pesquisadas foram visitadas em momentos distintos, objetivando compreender a rotina da instituição e a inserção no cenário da pesquisa. Durante as visitas iniciais foram identificadas 21 mulheres que se enquadravam nos critérios de inclusão da pesquisa, a saber: cumprir pena em regime fechado; compartilhar a prisão com filho ou com história anterior de compartilhamento. A pesquisa foi concluída com 17 entrevistadas, tendo em vista a saturação teórica dos dados ${ }^{(11)}$.

A coleta se deu mediante agendamento e em horário conveniente, em espaço físico indicado pela direção, sob a supervisão direta do agente penitenciário, atendendo recomendação institucional. Como instrumento da coleta de dados, utilizou-se questionário sociodemográfico, com a finalidade de caracterizar as participantes da pesquisa e entrevista semiestruturada áudio-gravada contendo questões referentes à vivência da maternidade no ambiente prisional.

Os resultados foram organizados e categorizados na perspectiva da análise de conteúdo, cumprindo à classificação dos elementos constitutivos, seguido por reagrupamento, segundo a analogia. A identificação das unidades de análise foi realizada após a leitura flutuante e exaustiva das entrevistas, e agrupadas por semelhança de conteúdo ${ }^{(12)}$. Posteriormente, realizou-se a decomposição das falas, que foram agrupadas em três categorias.

Esta pesquisa foi aprovada pelo Comitê de Ética em Pesquisa da Universidade Estadual da Paraíba, sob o número CAAE no 01340133000-12. As participantes do estudo assinaram o Termo de Consentimento Livre e Esclarecido (TCLE). A fim de resguardar o sigilo das participantes da pesquisa, bem como das instituições prisionais, adotou-se um sistema de identificação por códigos alfanuméricos, de conhecimento apenas da pesquisadora.

\section{RESULTADOS E DISCUSSÕES}

As entrevistadas eram predominantemente jovens, na faixa etária dos 18 aos 25 anos (52,9\%), solteiras (47\%), com média de três filhos $(70,5 \%)$, com relato de maternidade na adolescência $(70,6 \%)$, não professavam religião $(52,9 \%)$, com ensino fundamental incompleto (47\%), histórico de uso de álcool e/ou outras drogas antes do aprisionamento $(70,5 \%)$, sem profissão, aprisionadas por tráfico de drogas $(76,4 \%)$, reincidentes $(52,9 \%)$ e com situação jurídica provisória $(58,8 \%)$. Estavam com seus filhos no ambiente prisional $(64,7 \%)$, que os acompanharam após o aprisionamento materno (52,9\%).

\section{Sofrimento pela separação}

Em decorrência do aprisionamento materno constata-se o sofrimento pela separação dos seus filhos, como característica da vivência da maternidade para as participantes desse estudo.

Mesmo que, reconhecidamente, as condições para vivência da maternidade no cárcere sejam $\operatorname{adversas}^{(7)}$, a Constituição Federal Brasileira assegura a mulher presa o direito de permanecer com seus filhos, durante determinado período de encarceramento ${ }^{(13)}$.

Sobre este direito, a Lei de Execução Penal (LEP), de 1984, preconiza que os estabelecimentos penais destinados às mulheres sejam dotados de berçário, onde as condenadas possam cuidar de seus filhos, inclusive amamentá-los, no mínimo, até seis meses de idade. 
Atualmente, a Lei $\mathrm{n}-11.942$, de 28 de maio de 2009, acrescenta à LEP a obrigatoriedade de que as penitenciárias sejam dotadas de seção para gestantes, parturientes e de creche para abrigar crianças maiores de seis meses e menores de sete anos, com a finalidade de assistir a criança desamparada, cuja responsável estiver presa $^{(13)}$. Outrossim, o Estatuto da Criança e do Adolescente (ECA) prevê a permanência do filho junto a mãe no período de amamentação, mesmo que esta esteja privada de sua liberdade ${ }^{(14)}$.

Transcorridos os prazos legais, as crianças devem ser separadas de suas mães e deixadas sob os cuidados de outros responsáveis. Tal separação é apontada, pelas mulheres presas, como uma das maiores fontes de sofrimento em seus cotidianos ${ }^{(4)}$. Sofrimento este vivenciado tanto em decorrência da separação abrupta da criança quando concluído o período de amamentação, como nos casos onde a separação é periódica, ocorrendo ao término de cada visita familiar, conforme demonstram as falas que seguem:

Eu passei três meses só chorando por causa dele (1-6). É triste demais né? Aqui a pessoa pode estar presa, mas o que dói muito é a pessoa que a gente gosta estar longe de

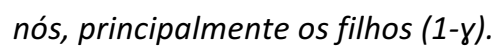

Quando estamos na visita, nós estamos muito felizes, mas depois que vai embora dá aquela "tranca no coração", choram os filhos, chora a mãe, choram as colegas que estão aqui, que também são mães (4- $\Omega$ ).

Por conhecer a limitação de tempo para conviver com seus filhos, enquanto privadas de liberdade, algumas falas das participantes do estudo demonstram tristeza pela separação iminente, como demonstra o trecho abaixo:

É uma tristeza, é uma tristeza a gente estar na cadeia e nessa situação, por causa que só tem um limite de ficar com o filho que é até seis meses" (1- $\alpha)$.
Por conhecer o sofrimento causado pela interrupção do vínculo, quando a criança é retirada do estabelecimento prisional, algumas mães presas optam por não estreitar os laços afetivos com seus filhos, a fim de evitar a dor a fim de evitar a dor das perdas futuras, como relatado a seguir:

Se eu demorar [para] sair, vou pedir que levem a menina embora, porque quanto mais rápido, o sofrimento é menor (3- $\alpha)$.

Assim, observa-se que além da carga imposta pelo cumprimento da pena a separação dos filhos é apontada como um dos maiores sofrimentos entre as mães presas, manifestos não apenas pela saudade, mas também pela falta de notícias, pela preocupação de não poderem acompanhá-los no seu desenvolvimento, pelo receio de esquecimento pelas crianças ou que representem mau exemplo para estes e, ainda, que o amor mãe-filho seja deslocado para a pessoa que ficou responsável pela guarda da criança durante o cumprimento da pena ${ }^{(4)}$.

Outro aspecto, responsável por tal sofrimento, se refere ao reconhecimento da apenada acerca de sua incapacidade em desempenhar funções maternas no ambiente prisional, visto que, em distintas sociedades, incluindo-se a brasileira, a definição do gênero feminino é tradicionalmente relacionado à esfera familiar e à maternidade ${ }^{(15)}$. Assim, a mulher é doutrinada socialmente, desde a mais tenra infância, a demonstrar o desejo pela maternidade, bem como a desempenhar habilidosamente ações de alimentação, higiene e cuidado para com seus futuros filhos ${ }^{(16)}$, provavelmente, por este motivo, as mulheres sentem-se indispensáveis e insubstituíveis no cuidado a seus filhos ${ }^{(17)}$.

Quando em situação de aprisionamento, as mães, que são historicamente as principais guardiãs das crianças, são atingidas por imagens negativas e estigmatizadas, uma vez que ferem o mito da boa mãe. Assim, por assimilar a função social que lhes é imputada e perceber a incapacidade em desempenhar plenamente 
as atribuições maternas, as participantes manifestam sofrimentos em suas falas:

Ah é muito difícil... meu menino passa da data de tomar as vacinas dele e eu não posso sair daqui para levar meu menino pra tomar as vacinas né? (2- $\alpha)$.

Aqui [...] quando a criança está doente, a gente não pode levar ela para o hospital, quem leva são as agentes, para vacinar quem leva são as agentes, essas coisas assim que é para mãe que estar fazendo, a gente fica limitada aqui (9- $\Omega)$.

Vale destacar as situações em que, apesar do sofrimento oriundo da separação, algumas mulheres renunciam a possibilidade de manter algum contato com seus filhos, na perspectiva de Ihes evitar malefícios, por saber antecipadamente que as crianças em situação de privação de liberdade permanecerão em ambientes insalubres, inclusive pela restrição da liberdade inerente as prisões ${ }^{(2)}$, como demonstra o seguinte recorte de fala:

É uma coisa muito ruim, porque ele não tinha liberdade de brincar, era preso na cela junto comigo, melhor ele [estar]

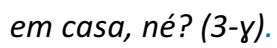

De antemão, sabe-se que a falta de estrutura física dos presídios, implica em dificuldade da manutenção da criança junto à mãe, pois a escassez de berçários nas unidades prisionais, faz com que crianças necessitem permanecer na cela junto com as demais prisioneiras ${ }^{(9)}$.

O comportamento materno exemplar pode decorrer também dos sentimento de culpa por manter os filhos junto a elas na prisão, em condições reconhecidamente desfavoráveis, o que desencadeia reações emocionais intensas de zelo e cuidado por parte das mães presas. Neste sentido, tais sensações de culpa possivelmente assemelham-se àquelas vivenciadas pelas mães HIV positivas que expuseram seus filhos à infecção ${ }^{(18)}$.

Outro motivo elencado pelas mulheres que optam por não conviver com seus filhos durante o cumprimento da pena relaciona-se ao rigor da revista que precede as visitas dos familiares, uma vez que exige o ato de despir a criança, considerado pelas participantes do estudo como algo humilhante e constrangedor:

Eu tenho saudade, mas eu prefiro que ela não venha, porque é muito rigorosa a visita[...] não era preciso tirar a roupa toda da criança (5- $\Omega$ ).

Quando as mães renunciam a presença dos seus filhos, enquanto encarceradas, provavelmente o façam para poupar-lhes emoções e sentimentos negativos dentro e fora da prisão, dado que são notórios os estigmas e a vulnerabilidade social que acompanham filhos de presidiárias ${ }^{(14)}$.

As opiniões divergem quanto à permanência da criança junto à mãe no ambiente prisional. Se por um lado enfatizam que é mutuamente benéfica a manutenção da relação mãe/filho, mesmo em condições de aprisionamento, de outro, reforçam a necessidade em afastar as crianças do ambiente precário, insalubre e hostil que constituem as prisões.

A má estruturação das instituições prisionais femininas dá-se, dentre outros motivos, aos baixos níveis de criminalidade e detenção de mulheres, o que, por sua vez, induziu equivocadamente, aos reformadores das prisões e aos criminólogos, a não se preocuparem com instituições prisionais femininas, deixando de atender as singularidades das mulheres, no que se refere, principalmente, à maternidade ${ }^{(19)}$.

\section{Consolo em meio à angústia}

Coexistem um fluxo compensatório no interior do sistema prisional feminino para as mesmas, ou seja, apesar das unidades prisionais serem consideradas pelas mães como um ambiente inadequado para suas crianças, a presença dos filhos na prisão favorece a retirada das mulheres das galerias prisionais e corrobora com a contenção de manifestações violentas por parte das apenadas, além de diminuir os casos de reincidência 
criminal $^{(20)}$. De maneira que algumas mães relacionam a presença dos filhos como um alento durante o aprisionamento.

Acho dez mil vezes melhor estar aqui com ele do que sem ele, que talvez eu já tivesse perdido a minha cabeça, já teria ido parar no "chapão", já teria arrumado muito problema, com um filho você pensa duas, três vezes antes de dar uma tapa $(9-\Omega)$.

Consoante as falas, observa-se que a presença da criança diminui o ócio e serve como alento, enquanto se aguarda a liberdade, bem como a presença de um filho funciona como elo familiar, relação essa estimada e priorizada pelas mulheres.

E Em relação da pequena que está comigo, no momento é o meu consolo, a presença dela- em meus braços me

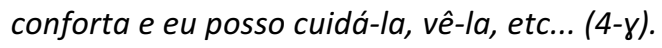

Eu não gosto nem de pensar, eu estou aqui e meus filhos longe, eu só não estou mais aperreada, porque, pelo menos, tem uma aqui já para eu ficar calma (1- $\Omega)$.

O sofrimento é menos, com o bebezinho tem com que se distrair, fica brincando, conversando, dá banho, faz a comidinha, dá a ele, troca fralda, ai tem como a gente suportar um pouco (6- $\Omega)$.

Ao favorecer a diminuição da ansiedade, dos sentimentos de solidão e, consequentemente, diminuir os riscos de depressão da apenada, a presença da criança junto às mães é capaz de conferir uma maior estruturação de personalidade e identidade da mulher presa, uma vez que, na maioria das vezes, as mães presas esforçam-se para manter bom comportamento em prol de seus filhos, por sua vez, o comportamento "melhorado" contribui com a manutenção da harmonia no estabelecimento prisional $^{(20)}$.

Por outro lado, o cárcere proporciona a aproximação entre mães e filhos, visto que, por vezes, fora da prisão o cuidado com as crianças é destinado a outrem, enquanto que no ambiente prisional, o cuidado integral com a higiene, a troca de fraldas, a amamentação passa a ser exclusiva da mãe presa, e tal contato faz com que as mulheres sintam-se mães ${ }^{(7)}$, e signifiquem a presença do filho junto a elas de forma positiva. Do outro, diz respeito aos privilégios a elas concedidos, enquanto estão com seus filhos na prisão e o receio em perdê-los:

A comida da casa é uma tristeza, mas aqui elas deixam entrar comida, uma fruta para nós, para criança, aqui elas ainda usam com a consciência (1- $\alpha)$.

Tendo filho a gente vem para aqui, tendo filho que não tem como ficar aqui vai para o corredor, que está "super" lotado $(6-\Omega)$.

Eu fico só imaginado, se for preciso levar o meu e eu voltar para o corredor (5- $\Omega)$.

As mulheres reconhecem as dificuldades que permeiam o funcionamento das prisões brasileiras, as quais dão claros sinais de esgotamento ${ }^{(3)} \mathrm{e}$, neste ambiente, a maternidade pode funcionar como o resgate da identidade e da bondade, e a postura de boa mãe favorece a aquisição de privilégios.

Talvez por esse motivo, mesmo que a mulher não tenha desejado ser mãe em determinado momento, evita manifestar essa ideia em palavras devido ao receio da culpabilização e/ou reconhecimento de desumanidade, semelhantemente ao que fazem as mulheres que provocam abortos, que na maioria das vezes, omitem os sentimentos avessos à gestação(21), como demonstra relato, a seguir:

Muitas cuidam, e outros e acho que não dá porque estão aqui, e sabe que se bater vai ter problema maior (9- $\Omega$ ). [Referência as punições passíveis de acontecer, tanto pelas apenadas quanto pela instituição em caso de negligência com as crianças].

Nesse contexto, observa-se, então, que as mães presas podem vir a ser julgadas e/ou julgar a si mesmas 
baseadas em valores de cunho moral, o que, possivelmente, acentua as dificuldades ao vivenciar a maternidade na prisão.

\section{Fragmentação familiar}

A fragmentação familiar decorrente do aprisionamento está presente no cotidiano das mães presas e implica negativamente na vivência da maternidade das participantes deste estudo.

A primeira e fundamental transformação na vida da apenada, não atribuído aos atos criminais ou ilegais, diz respeito a separação do seu grupo familiar, afetivo ou de convivência, portanto, torna-se relevante discutir as implicações que a vivência da maternidade privada de liberdade pode gerar na perda ou na fragmentação das relações familiares, deixando vulneráveis, principalmente, os filhos das apenadas ${ }^{(4)}$.

O contato entre pais e filhos caracteriza-se, geralmente, como irregular ou inexistente após o encarceramento, corroborando com a ideia de que um dos muitos efeitos nefastos do encarceramento é a quebra dos vínculos familiares ${ }^{(2,14)}$.

A família se configura na categoria social primária e, funciona como sistema classificatório e introdutório de construção do mundo social, bem como de proteção aos seus membros ${ }^{(23)}$, sendo atribuída às mulheres, nas mais distintas sociedades, a responsabilidade de manter a coesão das unidades familiares ${ }^{(16)}$.

No contexto do aprisionamento, a apenada tende a perder seu papel de mulher, esposa, mãe e filha, o que, por conseguinte, favorece a quebra dos vínculos familiares $^{(3)}$. Na fala que segue, destacam-se a fragmentação familiar e o distanciamento entre mães/filhos propiciados pelo encarceramento:

Ser mãe aqui? É difícil, porque sempre está separada de alguém, se estou com meu filho aqui ele está separado da avó, da irmã, se ele está com eles lá fora, eu estou sem nenhum. É doloroso, é nunca a família estar junta (3- $\Omega$ ).
Desta forma, o aprisionamento acaba por impactar negativamente nas relações de paternidade/maternidade e filiação. Ônus cuja sequela, por vezes, é irreparável. O trecho seguinte aponta também que a fragmentação familiar pode ser acentuada ao longo da pena:

Logo, no começo, quando eu cheguei aqui, eles choravam, mas hoje em dia, não choram mais não, eles ficam "doido" é para ir embora (3- $\alpha)$.

A fragmentação familiar, por sua vez, é favorecida e potencializada pelo abandono familiar subsequente ao aprisionamento. No tocante ao abandono familiar, estudos demonstram que, ao contrário do que ocorre com os homens, quando as mulheres são aprisionadas, na maioria das vezes, são abandonadas pelos seus familiares $^{(3)}$.

O abandono por parte das famílias das mulheres presidiárias pode ter diversas causas, como a distância das prisões femininas, as dificuldades socioeconômicos vivenciadas pela família das apenadas, os desgostos causados à família por seu envolvimento na criminalidade, a forma como os visitantes são recebidos nas prisões e os estigmas causados para os que ficam em portas de cadeia $^{(7)}$.Tal abandono origina a sensação de desamparo para as mulheres, e quando estas são mães, o sofrimento e a insegurança são potencializados pela inexistência de suporte familiar para cuidar de seus filhos, enquanto cumprem a pena, como enfatizam as falas:

Eu fico pedindo as agentes também que pelo amor de Deus que arrumem alguém pra ficar com meu filho até eu $\operatorname{sair}(2-\alpha)$.

É triste saber, que nem tem um caso aqui de uma amiga minha que está com a criança, ela fica dizendo direto, se lamentando, que a criança dela já está perto de seis meses e não tem quem cuide lá fora (1- $\alpha)$.

Os mesmos pressupostos culturais que associam a mulher à maternidade, responsabilizando-a pela coesão 
familiar e educação dos filhos, também reforçam a fragmentação familiar no caso do aprisionamento feminino, visto que, sendo a mulher presidiária, sua imagem passa a ser associada a características negativas que a "impossibilitam" de exercer adequadamente a maternidade ${ }^{(14)}$. Por este motivo é tão comum o abandono familiar e a quebra de vínculos entre mães e filhos, que muitas vezes, perpassa o período de encarceramento

A solidariedade emerge no contexto prisional feminino frente à carência de suporte externo, agravado pelo abandono familiar, assim, as mães presas, em muitas situações, contam com o auxílio das demais apenadas:

No local onde estou, apesar de não poder dar a ela o que toda criança precisa, está sendo tratada muito bem, todas ajudam a cuidar, se preocupam, enfim, ajudam no que podem (4- $)$.

Todavia, se a maternidade não é fácil para as mulheres que dividem esse momento com marido/companheiro, familiares e amigos, certamente não será para presidiárias que convivem em ambiente fechado, com outras mulheres desconhecidas, que podem ser prestativas, mas incapazes de suprir a falta da família ${ }^{(2)}$. Deste modo, torna-se pertinente considerar situações onde a fragmentação familiar precede o encarceramento, a exemplo dos casos em que ocorre envolvimento materno com álcool e/ou outras drogas, o que por sua vez, propicia situações de violência entre mães e filhos ${ }^{(22)}$.

Paradoxalmente ao abandono familiar, o aprisionamento materno provoca outro fenômeno: a sobrecarga das avós pelos cuidados dos filhos das apenadas. Estas, não raras vezes ficam responsáveis pelos netos, como identificado nas falas destas participantes:

Minha mãe quem cuida dos netos, e cuida muito bem, mas eu quero sair e cuidar deles, porque ela já cuida dos meus e dos [filhos] da minha irmã (3- $\Omega$ ).
A minha mãe está com meus outros filhos, ela está ocupada também, meu pai tinha falecido e ela está andando atrás do INSS (9- $\Omega$ ).

Os casos nos quais as avós, sobretudo as maternas, participam do cuidado e da educação dos seus netos são frequentes, seja pela crescente participação da mulher no mercado de trabalho, seja nos casos de gravidez na adolescência, divórcios, uso de drogas ou, ainda, nos casos de morte paterna/materna ${ }^{(23)}$. Acrescente-se os casos de aprisionamento, em que o cuidado das crianças é, corriqueiramente, transferido para os familiares.

No entanto, embora estudos demonstrem que as avós apreciam o contato com seus netos e gostam de participar de sua vida e criação, faz-se necessário atentar para o fato que havendo um elevado índice de internas com suas famílias em situação de vulnerabilidade social, o cuidado dos netos atribuídos às avós, pode se constituir em sobrecarga para estas, seja de ordem financeira ou na execução de atividades com cuidados primários em um período da vida, onde fisiologicamente necessita-se de maior repouso ${ }^{(24-25)}$.

Sendo o cuidado dos filhos, muitas vezes, transferidos as avós maternas, é mister considerar duas situações antagônicas que podem ocorrer mesmo após a liberdade das mães presidiárias, a abnegação permanente dos filhos, deixando-os sob tutela permanente das avós ou a disputa pela guarda e amor das crianças. Ambas as situações são capazes de perpetuar a fragmentação familiar, decorrente do encarceramento materno.

\section{CONSIDERAÇÕES FINAIS}

Para as participantes do estudo, a vivência da maternidade ganha contornos distintos daqueles vivenciados por mulheres em liberdade, a exemplo do sofrimento decorrente da separação dos filhos. Situações em que as mães presidiárias optam por não usufruir dos direitos de conviver com seus filhos na prisão, são comuns visto que as mulheres identificam o ambiente prisional 
como inadequado para permanência destes, ainda que a presença dos filhos proporcione consolo em meio a um contexto de privações.

O aprisionamento causa fragmentação familiar e, consequentemente, ruptura no vínculo entre mães e filhos, fato ocorrido, sobretudo, pelo abandono familiar vivenciado por muitas presidiárias.

Grande parte dos estudos que envolvem o binômio mãe e filho no ambiente prisional abordam aspectos epidemiológicos, deste modo, acredita-se na contribuição deste estudo ao permitir a aproximação entre os campos técnicos científicos e culturais das penitenciárias e a compreensão da maternidade vivenciada neste ambiente, o que poderá subsidiar o direcionamento de políticas de saúde pública capazes de beneficiar o binômio mulher-criança no contexto do aprisionamento. Para tanto, a partir dos dados elucidados neste estudo, sugere-se a inclusão da saúde penitenciária nos componentes curriculares e nas atividades de estágio dos acadêmicos da área de saúde, com vistas a garantir

\section{REFERÊNCIAS}

1. Ministério da Justiça [Internet]. Brasília: Ministério da Justiça (BR) [acesso em: 30 jun 2015]. InfoPen - Estatística. Disponível em: http://portal.mj.gov.br/data/Pages/MJD574E9CEITEMIDC37B2AE94C6 840068B1624D28407509CPTBRIE.htm.

2. Anjos SJSB, Ribeiro SG, Lessa PRA, Nicolau AIO, Vasconcelos CTM, Pinheiro AKB. Fatores de risco para o câncer de colo do útero em mulheres reclusas. Rev Bras Enferm [Internet]. 2013 [acesso em: 30 jun 2015];66(4):508-13. Disponível em: http://dx.doi.org/10.1590/S003471672013000400007.

3. Oliveira LV, Costa GMC, Medeiros KKAS, Cavalcanti AL.

Epidemiological profile of female detainees in the Brazilian state of Paraíba: a descriptive study. Online Brazilian J Nurs [Internet]. 2013 [acesso em: 30 jun 2015];12(4). Disponível em: http://dx.doi.org/10.5935/1676-4285.20134284.

4. Araújo ANV, Moura LB, Ferreira Neto EA, Bispo TCF. Percepção de mães presidiárias sobre os motivos que dificultam a vivência do binômio. Rev Enferm Contemp [Internet]. 2014 [acesso em: 30 jun 2015];3(2):131-42. Disponível em: http://dx.doi.org/10.17267/23173378rec.v3i2.411.

5. Gois SM, Santos Junior HPO, Silveira MFA, Gaudêncio MMP. Para além das grades e punições: uma revisão sistemática sobre a saúde penitenciária. Cien Saude Colet [Internet]. 2012 [acesso em: 30 jun 2015];17(5):1235-46. Disponível em: http://dx.doi.org/10.1590/S141381232012000500017.

6. Galvão MCB, Davim RMB. Ausência de assistência à gestante em situação de cárcere penitenciário. Cogitare Enferm [Internet]. 2013 aperfeiçoamento de habilidades e competências para uma abordagem profissional integral e humana.

Ademais, cabem aos gestores programar ações de formação continuada aos profissionais de saúde, responsáveis pelo atendimento da população presa, tanto no ambiente prisional, quanto nos espaços extramuros. Conclui-se que é mister implantar ações intersetoriais que favoreçam a relação mãe e filho no contexto do aprisionamento.

Ao longo da execução da pesquisa, percebeu-se a importância de apreender a percepção dos outros sujeitos indiretamente envolvidos no processo de maternidade das mulheres presas. Isso, associado as relações conflituosas na carceragem e a presença dos agentes penitenciários durante as entrevistas se constituíram limitações desta pesquisa, bem como se constituem em lacunas para estudos futuros, especialmente, nas exploração de das relações/vivências da maternidade das presidiárias com conjugues, familiares, profissionais de saúde e agentes penitenciários.

[acesso em: 30 jun 2015];18(3):452-9. Disponível em: http://dx.doi.org/10.5380/ce.v18i3.33554.

7. Silva EF, Luz AMH, Cecchetto FH. Maternidade atrás das grades [Internet]. Enfermagem em Foco [acesso em: 30 jun 2015];2(1):33-7. Disponível em:

http://revista.cofen.gov.br/index.php/enfermagem/article/view/71. 8. Foucault M. Vigiar e punir - história da violência nas prisões. Petrópolis: Vozes; 1987.

9. van den Bergh B, Gatherer A, Fraser A, Moller L. Imprisonment and women's health: concerns about gender sensitivity, human rights and public health. Bull World Health Organ [Internet]. 2011 [acesso em: 30 jun 2015];89(9):689-94. Disponível em:

http://dx.doi.org/10.2471/BLT.10.082842.

10. Barcinski M, Cúnico SD. Os efeitos (in)visibilizadores do cárcere: as contradições do sistema prisional. Psicologia [Internet]. 2014 [acesso em: 30 jun 2015];28(2):63-70. Disponível em:

http://www.scielo.mec.pt/scielo.php?script=sci_arttext\&pid=S087420492014000200006\&lng=pt\&nrm=iso\&tlng=pt.

11. Bauer MW, Gaskell G. Pesquisa Qualitativa com texto, imagem e som: um manual prático. 8a Ed. Petrópolis: Vozes; 2010.

12. Bardin L. Análise de conteúdo. Lisboa: Edições 70, 1977; 2011.

13. Oliveira EF, Teixeira MC. O Direito Fundamental das Presidiárias e seus Filhos ao Aleitamento Materno. Rev do Curso Direito [Internet]. 2014 [acesso em: 30 jun 2015];11(11):68-101. Disponível em: http://dx.doi.org/10.15603/2176-1094/rcd.v11n11p68-101. 14. Melo DC, Gauer G. Vivências da maternidade em uma prisão feminina do Estado do Rio Grande do Sul. Sau. \& Transf Soc. [Internet] 
2011 [acesso em: 30 jun 2015];1(3)113-21. Disponível em:

http://incubadora.periodicos.ufsc.br/index.php/saudeetransformacao/

article/view/654.

15. Fonseca C. Mães "abandonantes": fragmentos de uma história silenciada. Rev Estud Fem [Internet]. 2012 [acesso em: 30 jun

2015];20(1):13-32. Disponível em: http://dx.doi.org/10.1590/S0104026X2012000100002.

16. Ostos NSC. A questão feminina: importância estratégica das mulheres para a regulação da população brasileira (1930-1945). Cad Pagu [Internet]. 2012 [acesso em: 30 jun 2015];(39):313-43. Disponível em: http://dx.doi.org/10.1590/S0104-83332012000200011.

17. Martins EMCS, Ataíde MBC, Silva DMA, Frota MA. Vivência de mães no cuidado à criança diabética tipo I. Rev Rene [Internet]. 2013 [acesso em: 30 jun 2015];14(1):42-9. Disponível em:

http://www.revistarene.ufc.br/revista/index.php/revista/article/view/ 1332.

18. Galvão MTG, Cunha GH, Lima ICV. Mulheres que geram filhos expostos ao vírus da imunodeficiência humana: representações sociais da maternidade. Rev. Eletr. Enf. [Internet]. 2014 [acesso em: 30 jun 2015];(16(4):804-11. Disponível em:

http://dx.doi.org/10.5216/ree.v16i4.22760.

19. Maia CN, Neto FS, Costa M, Bretas MLB. História das prisões no Brasil. Volume 1. Rio de Janeiro: Rocco; 2009.

20. Oliveira I.Costa g.Miranda f. O significado da maternidade para presidiárias Rev enferm UFPE on line [Internet]. 2015 [acesso em: 30 jun 2015];9(2):851-7. Disponível em:

http://www.revista.ufpe.br/revistaenfermagem/index.php/revista/arti cle/view/6950.

21. Souza ZCS do N, Diniz NMF. Aborto provocado: o discurso das mulheres sobre suas relações familiares. Texto \&amp; Context Enferm [Internet]. Texto contexto - enferm. 2011 [acesso em: 30 jun 2015];20(4):742-50. Disponível em:

http://www.scielo.br/scielo.php?script=sci_arttext\&pid=S010407072011000400013\&lng=en\&nrm=iso\&tlng=pt.

22. Bittar DB, Nakano AMS, Silva MAI, Roque EMST. Violência intrafamiliar contra crianças e adolescentes na percepção de mães agressoras. Rev. Eletr. Enf. [Internet]. 2012 [acesso em: 30 jun 2015];14(4):771-8. Disponível em:

http://dx.doi.org/10.5216/ree.v14i4.15739.

23. Cardoso VS, Costa LF. “Não me Perguntem com Quem Eu Quero Ficar": A Voz da Criança e os Avós no Pedido de Guarda Judicial. Rev Psicol da IMED [Internet]. 2014 [acesso em: 30 jun 2015];6(1):58-64. Disponível em: http://dx.doi.org/10.18256/2175-5027/psicoimed.v6n1p58-64.

24. Pacheco MEAG, Alves SMM. A função social dos idosos avós na contemporaneidade: uma análise preliminar da estrutura familiar [Internet]. Conhecimento \& Diversidade. 2013 [acesso em: 30 jun 2015];4(8):93-103. Disponível em:

http://www.revistas.unilasalle.edu.br/index.php/conhecimento divers idade/article/view/974.

25. Santos TM, Silva SSC, Pontes FAR. A participação dos avôs no cuidado dos netos em uma comunidade ribeirinha amazônica [Internet]. Revista Psicologia - Teoria e Prática. 2011 [acesso em: 30 jun 2015];13(1):182-97. Disponível em:

http://editorarevistas.mackenzie.br/index.php/ptp/article/view/3029.

Recebido: 09/05/2014.

Aceito: 04/03/2015.

Publicado: 30/06/2015. 